\title{
The Effect of Hyperoxic Exposure on Antioxidant Enzyme Activities of Alveolar Type II Cells in Neonatal and Adult Rats
}

\author{
SUSA.N E. KEENEY, SAMUEL E. CRESS, SUSAN E. BROWN, AND AKHIL BIDANI \\ Departments of Pediatrics and Internal Medicine, The University of Texas Medical Branch, \\ Galveston, Texas 77550
}

\begin{abstract}
Neonatal animals of several species are more tolerant of hyperoxic exposure than are adults, but the mechanisms of increased neonatal tolerance are unknown, as are the cell types, if any, that contribute to oxygen resistance. We studied the effect of in vivo exposure to $85 \%$ oxygen for $72 \mathrm{~h}$ on the activities of the antioxidant enzymes, glutathione peroxidase, catalase and superoxide dismutase (SOD), in alveolar type II cells and whole lung from adult and neonatal rats. Baseline antioxidant enzyme activities were generally lower in neonatal type II cells compared with adults. Baseline enzyme activities did not differ in neonatal type II cells and lung homogenates except for lower catalase activity in type II cells. Hyperoxic exposure resulted in $35-38 \%$ increases in antioxidant enzyme activities in neonatal whole lung. In neonatal type II cells, SOD activity increased by $170 \%$ after hyperoxia, whereas catalase and glutathione peroxidase were not significantly changed. In the adult whole lung, hyperoxic exposure resulted in increases in only glutathione peroxidase activity, whereas in adult type II cells there was a significant decrease in SOD activity after $\mathrm{O}_{2}$ exposure. Therefore, although baseline antioxidant enzyme activities were not higher in neonatal type II cells compared with whole lung, there were differences in the antioxidant enzyme responses of adult and neonatal type II cells to hyperoxia, particularly with respect to SOD. The ability of the neonatal type II cell to respond to hyperoxia with an early increase in SOD activity may contribute to the enhanced oxygen tolerance of the neonate. (Pediatr Res 31: 441-444, 1992)
\end{abstract}

Abbreviations

CAT, catalase

SOD, superoxide dismutase

GPX, glutathione peroxidase

It has been demonstrated repeatedly that neonatal animals of several species, including the rat, are more resistant than adults to the lethal effects of exposure to high concentrations of oxygen (1-4). The mechanisms of the increased oxygen tolerance of the neonate compared with that of the adult are incompletely understood. Higher neonatal tolerance may be related to differences

Received March 26, 1991 ; accepted December 4, 1991.

Address for correspondence and reprint requests: Susan E. Keeney, M.D., Division of Perinatal Pediatrics, Rt E26, Department of Pediatrics, University of Texas Medical Branch, Galveston, Texas 77550.

Supported by the American Lung Association (Basic Research Grant) and an Institutional Small Grant, University of Texas Medical Branch and in part by the Moody Foundation. in cellular protective mechanisms, such as the antioxidant enzyme system, which includes the enzymes GPX, CAT, and SOD (5). It is known that the neonatal animal responds to exposure to $>95 \% \mathrm{O}_{2}$ with increased activities of antioxidant enzymes in the lung, an enzyme response not observed in the adult lung $(2-4)$.

The particular cell types that may be responsible for increases in antioxidant enzyme activity in the neonate have not been identified. Previous investigations of adult type II cells have produced conflicting data on whether antioxidant enzyme activities are higher in type II cells than in whole lung and whether antioxidant enzyme activities in type II cells increase after hyperoxia $(6,7)$. One previous investigation of neonatal type II cells has suggested that antioxidant enzyme activities do not increase in this cell type after hyperoxia (8). However, because the type II cell is relatively resistant to oxygen damage compared with other cell types and appears to be important for proliferation and repair of the pulmonary epithelial lining after damage $(5,9)$, we hypothesized that this cell might play a role in neonatal tolerance. This study was designed to test the hypotheses that 1 ) baseline (air-exposed) antioxidant enzyme activities would be higher in neonatal type II cells than in whole lung and 2) the activities of the antioxidant enzymes in neonatal type II cells would rise to a greater extent in response to hyperoxia than those in adult type II cells. We measured antioxidant enzyme activities of neonatal and adult type II alveolar cells and lung homogenates after in vivo exposure of rats to $85 \% \mathrm{O}_{2}$ or air for $72 \mathrm{~h}$ to compare neonatal and adult responses.

\section{MATERIALS AND METHODS}

Animals. Viral-antibody-free adult male Sprague-Dawley rats wcighing 175-225 g were obtained from Sasco Inc. (Houston, TX). Timed gestation pregnant rats were obtained from the same supply company and were allowed to spontaneously deliver. Neonatal rats from four litters (eight to 12 neonates per litter) were pooled after spontaneous delivery to eliminate differences in individual litters; they were randomly allocated into four groups for gas exposures, which were performed as described below. Adult animals were allowed free access to water and rat food during gas exposures. Pups were allowed to nurse ad libitum; dams were switched between oxygen and air neonatal exposure groups every $24 \mathrm{~h}$ to control for possible nutritional deprivation in the oxygen exposure group. All experiments were performed humanely and with the approval of the Animal Care and Use Committee of the University of Texas Medical Branch.

Chemicals. Fluorocarbon FC-75 was the generous gift of $3 \mathrm{M}$ Company (St. Paul, MN), newborn bovine serum and trypsin 1:250 were obtained from Flow Laboratories (McLean, VA), metrizamide was from Accurate Chemical Corp. (Westbury, NY), Triton X-100 from Aldrich Chemical Co. (Milwaukee, WI), and elastase was from Worthington Biochemical (Freehold, 
NJ). Unless otherwise specified, all other chemicals were obtained from Sigma Chemical Co. (St. Louis, MO) and were of the highest grade commercially available.

Gas exposures. An oxygen concentration of $85 \%$ was chosen because it is sublethal for adult rats and $100 \%$ survival was desired during the 3-d study period. Neonatal animals were studied at the same $\mathrm{O}_{2}$ concentration to compare antioxidant enzyme activities in both age groups. Exposures to either $85 \%$ $\mathrm{O}_{2}$ or air (control) were performed in air-tight plastic cages; total exposure time was $72 \mathrm{~h}$. Oxygen and air were blended to achieve a concentration of $85 \% \mathrm{O}_{2}$ using a Bennett air-oxygen mixer (Puritan-Bennett Corp., Los Angeles, CA), and $\mathrm{O}_{2}$ concentration was analyzed at least every $8-12 \mathrm{~h}$ with a Ventronics model 5528 oxygen monitor (Temecula, CA). Oxygen concentrations remained at $85 \pm 2 \%$ and ambient $\mathrm{CO}_{2}$ exiting the cage was verified to be $<1 \%$, using a Fyrite test kit (Bacharach Instruments, Pittsburgh, PA). Gas was humidified and flow rates for both groups were maintained at $5 \mathrm{~L} / \mathrm{min}$. Cages were opened every $24 \mathrm{~h}$ to switch dams and to change food and bedding.

Isolation of type II alveolar cells. Adult type II cells were isolated using the method of Dobbs et al. (10). Protease solution consisting of $2.0 \mathrm{U} / \mathrm{mL}$ elastase, $0.0025 \%$ trypsin, and $0.001 \%$ DNAase was instilled into the trachea for $30 \mathrm{~min}$ at $37^{\circ} \mathrm{C}$. After discontinuous metrizamide density gradient centrifugation, the resulting cell suspension was purified by the method of Dobbs $e t$ al. (11) by plating on Petri dishes coated with rat $\mathrm{IgG}$ at a concentration of $0.5 \mathrm{~g} / \mathrm{L}$ in $50 \mathrm{mM}$ Tris, pH 9.5 . After $1 \mathrm{~h}$ of incubation at $37^{\circ} \mathrm{C}$ in $5 \% \mathrm{CO}_{2}$, the nonadherent cellular suspension, enriched in type II cells, was recovered and counted on a hemocytometer.

Neonatal type II cells were isolated in a similar manner except that the lungs were excised after perfusion of the pulmonary artery, chopped, and exposed to a protease solution of 5.8 $\mathrm{U} / \mathrm{mL}$ elastase, $0.008 \%$ trypsin, and $0.001 \%$ DNAase for $30 \mathrm{~min}$. Further purification was similar to that used for adult cells, except that an additional differential adherence for $45 \mathrm{~min}$ was performed to remove fibroblasts and other readily adherent cells. Hypotonic lysis of red blood cells in the neonatal preparations was performed by incubation ( $1 \mathrm{~min}$ at room temperature) in hypotonic solution $\left(28 \mathrm{mM} \mathrm{NaCl}, 1.0 \mathrm{mM} \mathrm{NaHPO}_{4}, 0.34 \mathrm{mM}\right.$ $\mathrm{KH}_{2} \mathrm{PO}_{4}, 0.62 \mathrm{mM} \mathrm{KCl}, \mathrm{pH} 7.4$ ), followed by rapid restoration of isotonicity. Purity was assessed using a tannic acid/polychrome stain (12), and viability by trypan blue exclusion.

Type II cells isolated from the lungs of two adult male rats or from two litters of neonatal rats were pooled for enzyme assays. Freshly isolated cells were resuspended at a concentration of $2 \times$ $10^{7}$ cells $/ \mathrm{mL}$ in $50 \mathrm{mM}$ potassium phosphate buffer, $\mathrm{pH} 7.4$, with $1.0 \mathrm{mM}$ EDTA and $0.05 \%$ Triton X-100. Cells were sonicated on ice for $40 \mathrm{~s}$ using a Branson sonifier model 450 with a microtip (Branson Ultrasonics Corp., Danbury, CN). The resultant sonicate was centrifuged at $20000 \times g$ for $10 \mathrm{~min}$ at $4^{\circ} \mathrm{C}$, and the supernatant solution was frozen at $-20^{\circ} \mathrm{C}$. Assays of GPX and CAT activities were performed within $3 \mathrm{~d}$ of isolation and SOD within $1 \mathrm{wk}$.

Preparation of lung homogenates. Whole lung homogenates were prepared after lungs were perfused and copiously rinsed in ice-cold PBS. In adult rats, perfusion of the lungs via the pulmonary artery resulted in lung tissue that was grossly free of blood. Perfusion of the neonatal pulmonary artery was technically more difficult, and inadequately perfused lungs were discarded from the pooled sample before homogenization. For this project, the enzymes were not corrected for blood contamination by concurrent $\mathrm{Hb}$ measurement. In other similarly prepared samples, blood contamination accounted for $<5 \%$ of SOD, $<1 \%$ of GPX, and $<10 \%$ of CAT activity. Adult lungs were suspended in $20 \mathrm{~mL}$ of homogenization buffer $(50 \mathrm{mM}$ potassium phosphate buffer, 1.0 mM EDTA, pH 7.4) per lung, and neonatal lungs from one litter were suspended in $10 \mathrm{~mL}$ of buffer. Lungs were homogenized on ice in a Brinkmann Polytron (Brinkmann Instruments, Inc., Westbury, NY) on setting 7, and the homog- enate was then centrifuged at $200 \times g$ to remove cellular debris. The supernatant solution was then sonicated and centrifuged at $20000 \times g$ for $10 \mathrm{~min}$.

Biochemical assays. GPX activity was measured using the method of Paglia and Valentine (13) with $t$-butyl hydroperoxide as substrate $(\mathrm{U}=\mathrm{nmol} \mathrm{NADPH} / \mathrm{min})$. CAT activity was assayed by measuring reduction of $\mathrm{H}_{2} \mathrm{O}_{2}$ at $240 \mathrm{nM}$ using the method of Holmes and Masters (14) (U $\left.=\mu \mathrm{mol} \mathrm{H}_{2} \mathrm{O}_{2} / \mathrm{min}\right)$. SOD was assayed using the method of Crapo et al. (15) by measuring the inhibition of cytochrome $c$ reduction by superoxide that was generated by xanthine and xanthine oxidase. Measurements were performed in the presence of $2 \mu \mathrm{M}$ potassium cyanide at $\mathrm{pH} 7.8$ at room temperature. One unit was defined as that causing $50 \%$ reduction in the rate of cytochrome $c$ reduction per min. We elected to measure total SOD rather than both $\mathrm{CuZn}$ and MnSOD because sample volume was limited. Protein was measured using the method of Lowry et al. (16) using BSA as standard. DNA was measured spectrophotometrically using the diphenylamine method of Richards (17) with calf thymus DNA as standard.

Statistical analysis. Data are expressed as mean \pm SEM. Probabilities of differences between groups were estimated by Mann-Whitney nonparametric tests and unpaired $t$ tests. A level of $p<0.05$ was considered to be statistically significant.

\section{RESULTS}

Mortality was negligible $(<5 \%)$ for both adult and neonatal rats, and there were no differences in mortality between air- and oxygen-exposed groups. Control adult rats gained an average of $25.1 \mathrm{~g}$ during the 3-d period; those exposed to hyperoxia lost an average of $13.8 \mathrm{~g}$. All neonatal rats gained weight during the exposure period, with the oxygen-exposed group gaining slightly less weight $(3.45 \mathrm{~g})$ than the control group $(4.09 \mathrm{~g})$. Yields of adult type II cells were $13.04 \times 10^{6}$ per rat for the air-exposed group and $12.0 \times 10^{6}$ per rat for the $\mathrm{O}_{2}$-exposed group. Yields of neonatal type II cells were $2.3 \times 10^{6}$ per rat and $1.08 \times 10^{6}$ per rat for the air- and $\mathrm{O}_{2}$-exposed groups, respectively. Purities of type II cell preparations were $88-92 \%$ for adults and $85-90 \%$ for neonatal rats; cell viability was $90-95 \%$ for both adult and neonatal preparations. Neither purity nor cell viability differed among exposure groups. Protein/DNA ratios were similar in type II cell preparations from both exposure groups, and these ratios did not differ between adult and neonatal type II cell preparations $(11.91 \pm 0.73$ versus $11.01 \pm 0.85)$. In adult lung homogenates, protein/DNA ratios were higher in the oxygenexposed groups $(41.27 \pm 4.68)$ than in control (air-exposed) groups $(27.44 \pm 3.68)$. There were no significant differences in protein/DNA ratios in neonatal lung homogenates for $\mathrm{O}_{2}$ and control (air-exposed) groups (17.21 \pm 1.47 and 15.76 \pm 1.05 , respectively). Because these ratios did not generally differ, enzyme activity data are presented with $\mu \mathrm{g}$ DNA as the denominator for analysis.

Baseline lung homogenate and type II cell enzyme activities in neonatal and adult rats. GPX and SOD activities were lower and CAT activity was higher in neonatal than in adult lung homogenates. CAT and SOD values in neonatal type II cells were 47 and $30 \%$ of adult type II cell values, respectively, whereas GPX activity was similar.

Enzyme activities in type II cells versus lung homogenates. Antioxidant enzyme activities in type II cells were compared with those in lung homogenates in the air-exposed (control) groups. Adult type II cells had lower GPX and higher CAT activities than adult lung homogenates, whereas SOD activity was comparable. Neonatal type II cells had lower CAT activity than neonatal lung homogenates; SOD and GPX activities did not differ.

Responses of adults to hyperoxia. Figure 1 summarizes the effects of hyperoxic exposure on antioxidant enzyme activities expressed per $\mu \mathrm{g}$ DNA in adult lung homogenates $(A)$ and adult 

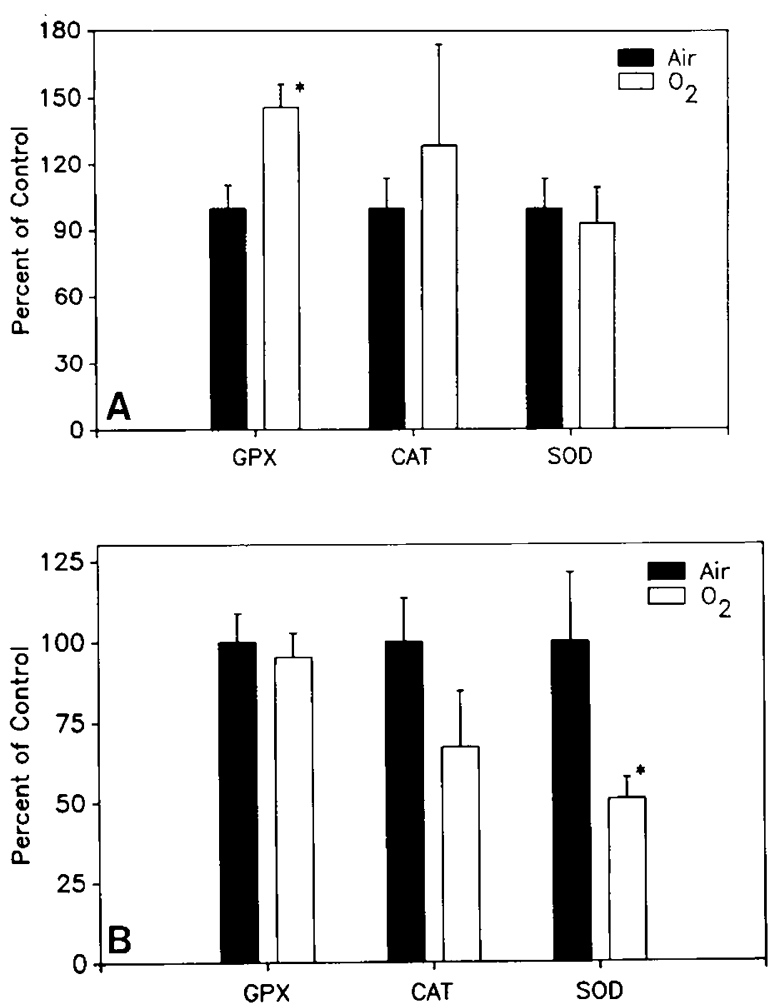

Fig. 1. Activities of GPX, CAT, and SOD in $(A)$ adult lung homogenates and $(B)$ adult type II cells per $\mu \mathrm{g}$ DNA. Data are expressed as percentage of air control + SEM. * indicates $p<0.05$ for air $v s \mathrm{O}_{2} . A$, Actual values are GPX air $2.92 \pm 0.31 \mathrm{U} / \mu \mathrm{g}$ DNA; GPX $\mathrm{O}_{2} 4.25 \pm 0.29$; CAT air $0.45 \pm 0.06$; CAT $\mathrm{O}_{2} 0.58 \pm 0.20$; SOD air $0.28 \pm 0.04$; SOD $\mathrm{O}_{2} 0.27 \pm 0.05 . B$, Actual values are GPX air $0.78 \pm 0.07 ; \mathrm{GPX} \mathrm{O}_{2} 0.74$ \pm 0.06 ; CAT air $1.12 \pm 0.15 ; \mathrm{CAT} \mathrm{O}_{2} 0.75 \pm 0.19$; $\mathrm{SOO}$ air $0.32 \pm 0.07$; and SOD $\mathrm{O}_{2} 0.16 \pm 0.02$.

type II cells $(B)$. In adult lung homogenates, exposure to $85 \%$ $\mathrm{O}_{2}$ for $72 \mathrm{~h}$ resulted in a significant increase in GPX, but no changes in CAT or SOD activities. In adult type II cells, hyperoxic exposure resulted in a significant decrease in SOD, but no changes in CAT or GPX activities.

Responses of neonates to hyperoxia. Figure 2 summarizes the effects of hyperoxic exposure on antioxidant enzyme activities expressed per $\mu \mathrm{g}$ DNA in neonatal lung homogenates $(A)$ and neonatal type II cells $(B)$. In neonatal lung homogenates, exposure to $85 \% \mathrm{O}_{2}$ for $72 \mathrm{~h}$ resulted in increases in GPX and CAT activities, but no significant increase in SOD. In neonatal type II cells, hyperoxic exposure resulted in an increase of SOD (170\%), but no changes in GPX or CAT activities.

\section{DISCUSSION}

We know of no previous comparisons of antioxidant enzyme activities in type II cells of neonates and adults. However, it is not surprising that antioxidant enzyme activities under air-exposed conditions were generally lower in neonatal type II cells compared with adults, as has previously been demonstrated in lung homogenates $(2,3)$. The slightly higher GPX activity in neonatal type II cells compared with adults differed from the pattern seen in lung homogenates, in which GPX was lower in the neonate. Several investigators $(2,3,18)$ have hypothesized that the ability of the neonate to increase antioxidant enzyme activities after hyperoxic challenge is likely to be more important for oxygen tolerance than baseline enzyme activities.

The enzyme activities in type II cells and lung homogenates were compared to roughly assess the relative contribution of type II cells to total lung antioxidant enzyme activities. In the neonate, our findings of no marked differences in antioxidant enzyme
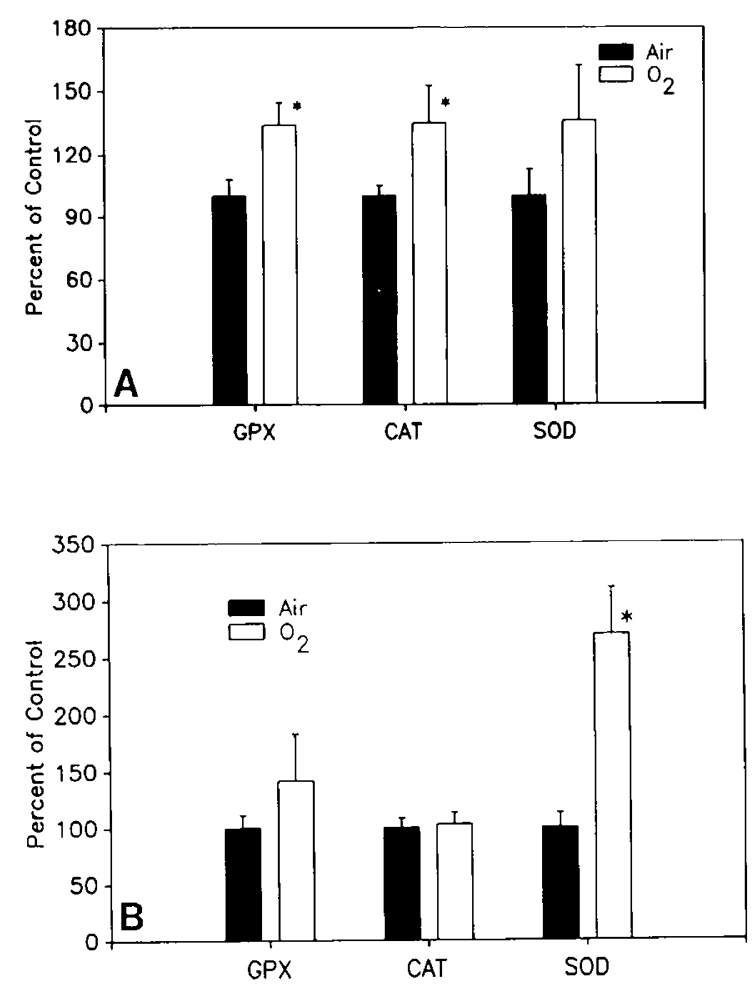

Fig. 2. Activities of GPX, CAT, and SOD in $(A)$ neonatal lung homogenates and $(B)$ neonatal type II cells per $\mu \mathrm{g}$ DNA. Data are expressed as percentage of air control + SEM. ${ }^{*}$ indicates $p<0.05$ for air $v s \mathrm{O}_{2}$. $A$, Actual values are GPX air $1.12 \pm 0.09 \mathrm{U} / \mu \mathrm{g}$ DNA; GPX $\mathrm{O}_{2} 1.55 \pm 0.12$; CAT air $0.64 \pm 0.03$; $\mathrm{CAT} \mathrm{O}_{2} 0.87 \pm 0.11$; SOD air 0.12 \pm 0.02 ; and $\mathrm{SOD} \mathrm{O}_{2} 0.17 \pm 0.03$. $B$, Actual values are GPX air $0.88 \pm$ $0.10 ; \mathrm{GPX} \mathrm{O}_{2} 1.26 \pm 0.37$; CAT air $0.49 \pm 0.04 ; \mathrm{CAT} \mathrm{O}_{2} 0.51 \pm 0.05$; SOD air $0.08 \pm 0.01$; and $\mathrm{SOD} \mathrm{O}_{2} 0.22 \pm 0.03$.

activities in type II cells and lung homogenates under air-exposed conditions agreed with those of Kennedy et al. (8). These data suggest that the neonatal type II cell does not offer protection to the lung from hyperoxia because of intrinsically high baseline antioxidant enzyme activities. In the adult rat, only CAT activity was significantly higher in air-exposed type II cells compared with whole lung, although SOD tended to be higher as well. The two previous investigations of antioxidant enzyme activities in adult type II cells after $7 \mathrm{~d}$ of $85 \% \mathrm{O}_{2}$ exposure reported conflicting data. Freeman et al. (6) showed no differences in activities of GPX, CAT, and total SOD between type II cells and lung homogenates, whereas Forman and Fisher (7) demonstrated higher activities of all enzymes in type II cells. However, the study of Forman and Fisher (7) differed in that type II cells were isolated with trypsin digestion and purified with $24 \mathrm{~h}$ of primary culture.

In the adult, hyperoxic induction of significant elevations of antioxidant enzymes was not demonstrated in either lung tissue or type II cells after $72 \mathrm{~h}$ of exposure. Only GPX activity was significantly increased in lung homogenates. These findings differ from previous investigations of adult whole lung preparations, which have reported increases in activities of all antioxidant enzymes after $5-7 \mathrm{~d}$ of exposure to $85 \% \mathrm{O}_{2}(6,19,20)$. This lack of enzyme induction was even more pronounced in adult type II cells, which demonstrated decreased CAT and SOD activities after $72 \mathrm{~h}$ of hyperoxic exposure, findings that differ from those of Freeman et al. (6), who demonstrated increases in SOD after $7 \mathrm{~d}$ of hyperoxic exposure. However, these differences in enzyme responses may reflect duration of exposure in previous studies, an exposure time of greater than $3 \mathrm{~d}$ being necessary for significant increases in enzyme activity to occur in adult type II cells. Study of enzyme activities after $7 \mathrm{~d}$ of $\mathrm{O}_{2}$ exposure may reflect a larger proportion of recovering or proliferating type II cells (21), 
whose responses to hyperoxia may differ from those of cells during the acute exposure period.

As has been reported by other investigators (2-4), we demonstrated increases of 35 to $38 \%$ in all antioxidant enzyme activities in neonatal lung homogenates after hyperoxic exposure. In neonatal type II cells, our findings of a marked increase in SOD in neonatal type II cells after hyperoxic exposure differ from those of Kennedy et al. (8), who reported decreases in CAT and no changes in SOD and GPX activities in neonatal type II cells after $4 \mathrm{~d}$ of exposure to $>95 \% \mathrm{O}_{2}$. Methodologic differences that could account for these results include oxygen concentration, duration of exposure, and method of type II cell isolation (trypsin versus elastase). In addition, although antioxidant enzyme activities in neonatal air-exposed rats did not differ in type II cells and lung homogenates, activity of SOD was higher in neonatal type II cells compared with lung homogenates after hyperoxic exposure. Because SOD may be particularly important for cellular protection against early, acute oxygen toxicity $(3,19,22)$, these findings suggest that the type II cell may play a special role in resistance of the neonatal lung to hyperoxia. This finding of increased SOD in the neonatal type II cell differed markedly from the response noted in the adult type II cell, in which activity of SOD actually decreased. The enhanced ability of the neonatal type II cell to mount an early response to acute oxygen toxicity with increased SOD activity may help to prevent early pulmonary damage in the neonate compared with the adult.

Certain methodologic difficulties are inherent in study of isolated cell populations and may account for some of the conflicts in published reports of enzyme responses in type II cells. To compare antioxidant enzyme activities in type II cells and lung homogenates, the isolated cells should be viable and similar to cells in the intact lung. Intracellular damage or alterations in intracellular enzyme activities in type II cells may occur as a result of certain protease mixtures used for tissue digestion $(23,24)$. However, this has not been reported to occur with elastase in regard to the antioxidant enzymes (6). The decrease in cell yield from oxygen-exposed animals noted in the present study has been previously reported (6-8) and attributed to difficulties of protease digestion of edematous lung. However, isolation of a selected cell population after hyperoxic exposure cannot be totally excluded.

These data in the term neonatal animal cannot be generalized to the preterm. The human preterm infant appears to be particularly susceptible to oxygen toxicity, the incidence of bronchopulmonary dysplasia increasing with degree of prematurity (25). Frank and Sosenko (18) have recently demonstrated that antioxidant enzyme activities in the preterm rabbit lung are lower than in the term lung and fail to increase in response to hyperoxic exposure. Further studies are needed to examine differences in antioxidant enzyme responses in the type II cells of term and preterm animals.

Acknowledgements. The authors thank Dr. David Rassin for advice and data analysis and Dr. Connie Baldwin, Jill Steven- hagen, and Linda Massa for assistance with preparation of the manuscript.

\section{REFERENCES}

1. Clark JM, Lambertson CJ 1971 Pulmonary oxygen toxicity: a review: Pharmacol Rev 23:37-133

2. Frank L, Bucher JR, Roberts RJ 1978 Oxygen toxicity in neonatal and adult animals of various species. J Appl Physiol 45:699-704

3. Yam J, Frank L, Roberts RJ 1978 Oxygen toxicity: comparison of lung biochemical responses in neonatal and adult rats. Pediatr Res 12:115-119.

4. Bucher JR, Roberts RJ 1981 The development of the newborn rat lung in hyperoxia: a dose-response study of lung growth, maturation, and changes in antioxidant enzyme activities. Pediatr Res 15:999-1008

5. Frank L 1985 Oxygen toxicity in eukaryotes. In: Oberley LW (ed) Superoxide Dismutase, Vol III. CRC Press, Boca Raton, FL, pp 2-34

6. Freeman BA, Mason RJ, Williams MC, Crapo JD 1986 Antioxidant enzyme activity in alveolar type II cells after exposure of rats to hyperoxia. Exp Lung Res 10:203-222

7. Forman HJ, Fisher AB 1981 Antioxidant enzymes of rat granular pneumocytes: constitutive levels and effect of hyperoxia. Lab Invest 45:1-6

8. Kennedy HA, Crouch LS, Warshaw JB 1989 Effect of hyperoxia on antioxidants in neonatal rat type II cells in vitro and in vivo. Pediatr Res 26:400403

9. Bowden DH, Adamson IYR 1971 The type 2 cell as progenitor of alveolar epithelial regeneration: a cytodynamic study in mice after exposure to oxygen. Arch Pathol 92:279-283

10. Dobbs LG, Geppert EF, Williams MC, Greenleaf RD, Mason RJ 1980 Metabolic properties and ultrastructure of alveolar type II cells isolated with elastase. Biochim Biophys Acta 618:510-523

11. Dobbs LG, Gonzalez R, Williams MC 1986 An improved method for isolating type II cells in high yield and purity. Am Rev Respir Dis 134:141-145

12. Mason RJ, Walker SR, Shields BA, Henson JE, Williams MC 1985 Identification of rat alveolar type II epithelial cells with a tannic acid and polychrome stain. Am Rev Respir Dis 131:786-788

13. Paglia DE, Valentine WN 1967 Studies on the quantitative and qualitative characterization of erythrocyte glutathione peroxidases. J Lab Clin Med 70:158-159

14. Holmes RS, Masters CJ 1970 Epigenetic interconversion of the multiple forms of mouse liver catalase. FEBS Lett 11:45-48

15. Crapo JD, McCord JM, Fridovich 11978 Superoxide dismutases, preparation and assay. In: Fleischer S, Packer L (eds) Methods of Enzymology, Vol 53(D). Academic Press, New York, pp 382-393

16. Lowry OH, Rosebrough NJ, Farr AL, Randall FJ 1951 Protein measurement with the Folin phenol reagent. J Biol Chem 193:265-275

17. Richards GM 1974 Modifications of the diphenylamine reaction giving increased sensitivity and simplicity in the estimation of DNA. Anal Biochem 57:369-376

18. Frank L, Sosenko IRS 1991 Failure of premature rabbits to increase antioxidant enzymes during hyperoxic exposure; increased susceptibility to pulmonary oxygen toxicity compared with term rabbits. Pediatr Res 29:292-296

19. Crapo JD, Sjostrom K, Drew RT 1978 Tolerance and cross-tolerance using $\mathrm{NO}_{2}$ and $\mathrm{O}_{2}:$ l. Toxicology and biochemistry. J Appl Physiol 44:364-369

20. Coursin DB, Cihla HP, Will JA, McCreary JL 1987 Adaptation to chronic hyperoxia: biochemical effects and the response to subsequent lethal hyperoxia. Am Rev Respir Dis 135:1002-1006

21. Northway WH, Rezeau L, Petriceks R, Bensch KG 1976 Oxygen toxicity in the newborn lung: reversal of inhibition of DNA synthesis in the mouse. Pediatrics 57:41-46

22. Crapo JD, Tierney DF 1974 Superoxide dismutase and pulmonary oxygen toxicity. Am J Physiol 226:1401-1407

23. Finkelstein JN, Mavis RD 1979 Biochemical evidence for internal proteolytic damage during isolation of type II alveolar epithelial cells. Lung 156:143154

24. Finkelstein JN, Shapiro DL 1982 Isolation of type II alveolar epithelial cells using low protease concentrations. Lung 160:85-98

25. Boynton BR 1988 Epidemiology of bronchopulmonary dysplasia. In: Merritt TA, Northway WH, Boynton BR (eds) Bronchopulmonary Dysplasia. Blackwell Scientific Publications, Boston, pp 19-32 